\title{
River Hydraulics during Flood Events: The Balkan Experiences
}

\author{
Mila Chilikova-Lubomirova ${ }^{1,}{ }^{*}$ and George Zaimes $^{2}$ \\ ${ }^{1}$ Institute of Mechanics - BAS, Fluid Mechanics Department, Acad. G. Bonchev Str., Block 4, 1113 \\ Sofia, Bulgaria \\ ${ }^{2}$ Eastern Macedonia and Thrace Institute of Technology (EMaTTECH), Dept. of Forestry and \\ Natural Environment Management, Drama, 66100, GREECE
}

\begin{abstract}
Nowadays the appearances of water extremes are frequently observed mainly because of anthropogenic and climate change influences. These extremes cause various impacts on the environment. With respect to river systems, floods are such events that are characterized with increasingly untypical high water levels that overflow river beds. In many cases, they cause extremely harmful impacts to human societies, accompanied with serious environmental damages and modifications. This paper focus on the problems connected to flood appearances and some of their possible related impacts on river systems. To better understand these, phenomenon main specifics with regard to its occurrence, behavior and possible consequences are summarized. Most commonly used methods for flood assessments are presented. Some real case floods and their impacts on the river hydraulics from the Balkans are briefly presented. To better explain floods and the reason-outcome-mitigation nexus related recent required and adopted EC, Bulgarian and Greece policies and practices in the area are outlined concisely with regard to prevention measures in the form of early warning systems, river restoration etc. The presented information address the experts in regards to knowledge, practices dissemination and enhancement, and the connection between experts and responsible decision makers that deal with flood mitigation and prevention.
\end{abstract}

\section{Introduction}

An increase in flood occurrences signifies the importance mitigating the phenomenon. To mitigate floods effectively all aspects regarding its genesis and behavior, its temporal and spatial distribution, severity and interconnection in regards to negative impacts concerning the environment and ecosystems need to be accounted for. Once the above are determined for a specific case study, the most appropriate measures can be selected. The adopted

\footnotetext{
*Corresponding author: milasemail@yahoo.com
} 
practices and policies of each country also play a key role in selecting the appropriate measures. When implementing measures both practices and policies need to be taken into account that will allow for the most efficient decisions to be taken and to lead to the most successful outcomes. To increase the awareness of these procedures while taking into account the importance of the local phenomenon features, this study will observe flood interconnection of the Balkans by emphasizing in Bulgaria and Greece. To achieve this some real cases studies from each country will be analyzed to better understand the casual connection between extreme events appearances and the related consequences. In addition the procedures, practices and legislation of flood management of both countries will be summarized. Of course this will be observed in the context of the EC adopted legislation such as the Water Directive 2000/60/EC [1] and the Flood Directive 2007/60/EC [2]. Taking into account the potential harmful results of floods, effective measures will be presented. In regards to the practices in the region the main focus will be on the possible prevention and mitigation measures in the context of early warning systems and river restoration practices implementation. This will be accomplished by clarifying the flood phenomenon, with regards to the developed processes nature, propagation and consequent impacts effects on the environment. Presented aspects will be examined from the river hydraulic side, considering it is the basis science in their physical processes development.

\section{Floods genesis and characteristics}

Floods are considered as an overflow of a large amount of water beyond its normal limits damaging normally dry land. They are a rapidly developed process evolved in a period of several minutes to several days, affecting different territories with regard to the local conditions, ranging from the mountains and plains to coastal areas, and from natural to urban areas. The events are temporally and spatially distributed irregularly. It is very hard to predict the exact place and severity of their occurrences although with the use of modern technologies this is becoming more efficient in large rivers but not as effective in small streams and flashy torrents.

Floods are generated by abnormal amounts of water. Its origin and state differs and depend on the local topography, ground cover, existing soil type, its physical properties and state, available artificial structures, etc. Typically, extreme precipitations are the main cause of such events. Another factor with a natural origin can be the sudden snowmelt. The two mention factors are also closely related to infiltration rates and when they are slow or negligible, as a result of the saturated or frozen ground, rock, artificial surface or road covering, they can significantly enhance flooding phenomena.

Floods are often associated with river systems (rivers, streams and torrents) where the flow rate exceeds the water transport capacity of the channel overflowing channel banks and flowing in to the adjacent floodplains and estuaries. Additional factors that contribute to flood appearances are the riverbed aggradation as observed in many cases by backwater effects. Aggradation is observed when the channel sediment volume is more than the flow can remove (sediment transport capacity). Sediment is therefore deposited into the channel making the existing river bed shallower, causing changes in the river channel gradient and decreasing flow velocities. Once the riverbanks height is reduced smaller discharge events can overflow them compared to past conditions. If substantial amounts of sediment are deposited in the channel, the river may be heavily modified and the river can create a new channel or divert to an old one to bypass the deposited sediment. Backwater effect occurs when the river flow meets obstructions that restrict its flow. Such effect can be observed in case of in-channel sediment deposits, river confluences, landslips of river banks, levees and dams, culverts, bridges, etc. Measures in regard to the natural or artificial structures e.g. lakes, reservoirs, wet zones, etc. can also lead to floods. Such events are connected to the 
exploitation and maintenance of river systems and related to artificial structures such as dams, levees, etc. and their control or emergency drainage. Natural disasters such as earthquakes or volcanic eruptions or severe artificial modification over the related existing structures areas can be a reason for flood events too. Floods caused by anthropogenic reasons should also not be ignored.

\section{Floods propagation}

Rivers are natural or man influenced geomorphologic formations that gather and transport all the watershed surface runoff and groundwater recharge to the river mouth. These processes are connected to the main river and its tributaries and are connected to natural or artificial structures such as lakes, reservoirs, wetlands, etc.

In a simple way, river systems physically can be considered as water and sediment transportation systems. With regard to the water (hydrological) cycle specifics, climate and anthropogenic impacts their flow rate fluctuate. The upper extremes of these fluctuations are considered as floods while the overall yearly normal flow is the baseflow. Observing the behavior of such extremes at a given point can be specified as the water amount that rises to a unique maximum (flood peak) and then recedes slowly. The progress of a flood event is presented on Fig. 1.

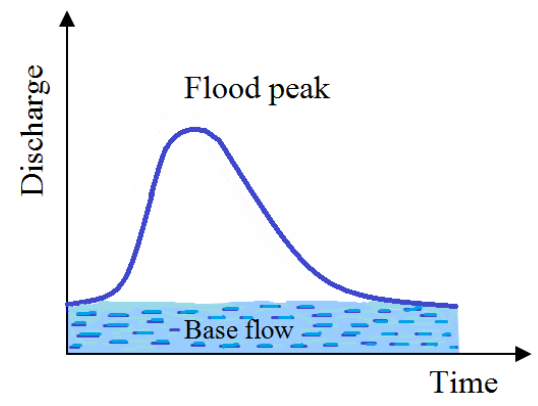

Fig. 1. Flood wave propagation at a certain point of the river

After the generation, flood is propagated as a wave along the river, its velocity and depth are continuously changing with time and distance with regard to the initial flood causes and the specifics of the river channel and/or floodplain area in case of an overflow.

\subsection{Physical description of the river flood propagation and hydraulic specifics}

Floods are temporally and spatially developed processes. Their physical behavior can be described by the main principle of hydrodynamics, utilizing the proper temporal-spatial scale and travelling time steps of the floods flow.

Flood water travelling downstream natural streams or artificial ones have typically unsteady flows. In case of significant precipitations, high snowmelt or floods that are created during the normal operation of the functioning and emptying of the hydraulic structures or canals, flow rises gradually. In regards to the basic hydraulic principles, river flood flows are considered as gradually varied unsteady flows, characterized by high temporal and spatial variation. Flood flow is three dimensional. It fluctuates with regard to the down-stream distance, depth and lateral position thus its specifics are closely connected 
to the river bed cross section properties and the channel hydraulic state. The flow surface profile also varies. It changes with regard to the downstream distance and lateral position.

Each fluid flow is a continuous phenomenon. A tree-dimensional description of the Eulerian concept is appropriate to study and understand flows. For this purpose the flow is observed as a control volume considering the behavior of its flow pressure, velocity, acceleration, and all other flow properties fields [3 - 9]:

$$
\begin{gathered}
\vec{v}=\vec{v}(x, y, z, t), \\
p=p(x, y, z), \\
T=T(x, y, z),
\end{gathered}
$$

where $\vec{v}$ is the velocity vector, determined by the time $t$ and space coordinates $x, y, z$; pressure is denoted by $p$ and flow temperature by $T$.

In case of real fluid studies, connected to river flows and flood waves, the following considerations must be assumed [3-9]: a) water is an isotropic Newton fluid b) river and floods flows are considered as an incompressible fluid and c) the temperature variations during the processes are neglected, because they are very small.

For such studies the following main equations are used: Continuity equation (preservation of mass); Momentum equations (preservation of momentum); Energy equation (preservation of energy).

Based on the description of the viscosity fluid flow behavior of the Navier-Stokes equations are derived as [3 - 9]:

$$
\begin{gathered}
\rho\left(\frac{\partial u}{\partial t}+u \frac{\partial u}{\partial x}+v \frac{\partial u}{\partial y}+w \frac{\partial u}{\partial z}\right)=-\frac{\partial p}{\partial x}+\mu\left(\frac{\partial^{2} u}{\partial x^{2}}+\frac{\partial^{2} u}{\partial y^{2}}+\frac{\partial^{2} u}{\partial z^{2}}\right)+\rho g_{x} \\
\rho\left(\frac{\partial v}{\partial t}+u \frac{\partial v}{\partial x}+v \frac{\partial v}{\partial y}+w \frac{\partial v}{\partial z}\right)=-\frac{\partial p}{\partial x}+\mu\left(\frac{\partial^{2} v}{\partial x^{2}}+\frac{\partial^{2} v}{\partial y^{2}}+\frac{\partial^{2} v}{\partial z^{2}}\right)+\rho g_{y} \\
\rho\left(\frac{\partial w}{\partial t}+u \frac{\partial w}{\partial x}+v \frac{\partial w}{\partial y}+w \frac{\partial w}{\partial z}\right)=-\frac{\partial p}{\partial x}+\mu\left(\frac{\partial^{2} w}{\partial x^{2}}+\frac{\partial^{2} w}{\partial y^{2}}+\frac{\partial^{2} w}{\partial z^{2}}\right)+\rho g_{z}
\end{gathered}
$$

where $u, v, w$, are the velocity components in regards to the coordinates $x, y, z$ and time $t$; $\mathrm{p}$ is the pressure, $\rho$ represents the density, $\mu$ represents the shear viscosity and $g=g(x, y, z)$ represents the acceleration, acting on the continuum.

The Navier-Stokes equations represent the balance of momentum. To estimate the flow description and practical solutions, additional data and information is needed. This information can be gain by the continuity equation and boundary data introduction.

Final solutions can be obtained within the help of numerical modeling and computer simulations with regard to the adopted assumptions and initial conditions. For this reason the following approaches are used in practice [4-11]: a) the method of characteristics b) the finite difference methods and c) the finite elements methods.

In the case of floods wave studies the length of propagation usually exceeds significantly the depth and width of the flow. In such conditions the more simple two or one dimensional models can be used. If we assume that the horizontal and vertical accelerations (and velocities) compared to the longitudinal ones can be neglected, a one dimensional investigation approach is applicable. Its theoretical basis follows:

The river floods wave, is described as a gradually varied unsteady flow, is characterized with significant variations on the flow depth and velocity thus the floods flow behavior can be described by the following [4 - 9]. Based on the Reynolds transport theorem, assuming 
water as a incompressible fluid the Continuity equation for a controlled volume can be presented as:

$$
\frac{d}{d t} \int_{x_{1}}^{x_{2}} A d x+A_{2} v_{2}-A_{1} v_{1}
$$

where $A$ is the flow area and $v$ represents the flow velocity at sections 1 and 2, denoted by the subscripts respectively.

Application of the Leibritz's theorem and the mean value theorem, assuming both $A$ and $\frac{\partial A}{\partial t}$ continuous with respect to both $x$ and $t$ yields that:

$$
\frac{\partial A}{\partial t}\left(x_{2}-x_{1}\right)+A_{2} v_{2}-A_{1} v_{1}=0
$$

Assuming $A v$ and $\frac{\partial v A}{\partial t}$ as continuous with respect to $x$ and $t$, and letting $\Delta x=x_{2}-x_{1}$ tend to zero gives:

$$
\frac{\partial A}{\partial t}+\frac{\partial A v}{\partial x}=0
$$

Accounting that flow rate is expressed by:

$$
Q=A v
$$

it changes as following:

$$
\frac{\partial A}{\partial t}+\frac{\partial Q}{\partial x}=0
$$

This equation represents the continuity equation in its conservation form.

For prismatic channels after some transformations equation (7) can be presented as:

$$
\frac{\partial y}{\partial t}+\left(\frac{A}{B}\right) \frac{\partial v}{\partial x}+v \frac{\partial y}{\partial x}=0
$$

where $B$ is the top surface width of the water.

Based on the Reynolds transport theorem the momentum equation for the control volume can be presented as:

$$
F_{\operatorname{Re} s}=\frac{d}{d t} \int_{x_{1}}^{x_{2}} v \rho A d x+\rho v_{2}^{2} A_{2}-\rho v_{1}^{2} A_{1}
$$

where $F_{\operatorname{Res}}$ is the resultant force acting on the control volume in the direction of flow.

After the application of both the Leibritz`s and mean value theorems (9) we get:

$$
\frac{F_{\operatorname{Re} s}}{\rho(\Delta x)}=\frac{\partial(A v)}{\partial t}+\frac{\partial}{\partial x}\left(A v^{2}\right) \text {. }
$$

Taking into account equation (6) we gave the following equation:

$$
\frac{F_{\operatorname{Re} s}}{\rho(\Delta x)}=\frac{\partial Q}{\partial t}+\frac{\partial}{\partial x}(Q v)
$$

The resulting force $F_{\operatorname{Re} s}$ on the controlled volume that is evaluated considering that: river channel is assumed prismatic therefore forces do not arise due to changes in the cross section; waves that are set up by the wind are not considered, therefore shear stress on the 
flow surface due to wind is neglected; open channel flow is considered. Flows in large water bodies such as estuaries and oceans are not considered here. Coriolis forces are also neglected. Net forces on the control volume comprise of: a) pressure force at section $1, b$ ) pressure force at section 2, c) the component of weight of water in the flow direction and d) the friction force due to shear between water and the channel sides and the channel bottom. These forces are estimated as follows:

Pressure forces at section 1 and 2 are presented by the following equations:

$$
\begin{aligned}
F_{1} & =\rho g A_{1} \overline{y_{1}} \\
\text { and } \quad F_{2} & =\rho g A_{2} \overline{y_{2}},
\end{aligned}
$$

where $\overline{y_{1}}$ and $\overline{y_{2}}$ are depths to the centroid of $A_{1}$ and $A_{2}, F_{1}$ act in the positive direction thus $F_{2}$ acts in the negative direction.

The component of the water weight in the direction of flow acts in the positive $\mathrm{x}$ direction and can be presented as:

$$
F_{3}=\rho g \int_{x_{1}}^{x_{2}} A S_{0} d x
$$

Friction force is:

$$
F_{4}=\rho g \int_{x_{1}}^{x_{2}} A S_{f} d x
$$

where $S_{0}$ is the channel bottom slope and $S_{f}$ is the friction slope. Friction slope may be estimated by using any friction loss equation such as the Manning equation. It acts in the negative $\mathrm{x}$-direction.

The forces substitution in eq. (11) leads to:

or

$$
\begin{gathered}
\frac{g\left(A_{1} \overline{y_{1}}-A_{2} \overline{y_{2}}\right)}{\Delta x}+g A\left(S_{0}-S_{f}\right)=\frac{\partial Q}{\partial t}+\frac{\partial}{\partial t}\left(A v^{2}\right) \\
\frac{\partial Q}{\partial t}+\frac{\partial}{\partial x}(Q v+g A \bar{y})=g A\left(S_{0}-S_{f}\right) .
\end{gathered}
$$

The final equation represents the momentum equation in the conservation form. Taking into account eq. (6) it can be presented as:

$$
\frac{\partial Q}{\partial t}+\frac{\partial}{\partial x}\left(\frac{Q^{2}}{A}\right)+g A \bar{y}-g A\left(S_{0}-S_{f}\right)=0 .
$$

Both equations (7) and (18), are known as the as Saint Venant equations and are widely implemented for flood wave propagation assessments. The presented equations are of great interest for surface hydrology and flood phenomena studies. The differential equations are practically applicable to calculate surface flows, considering the boundary and initial conditions in regard to river flows. Numerical modeling in general and the numerical hydraulics in particular are used commonly in practice, and are becoming popular methods in hydrology when taking into account the existing anthropogenic influence and human intervention on the natural state of water. The implementation of these numerical methods is widely applied in various computer programs and assessment tools [12, 13]. 


\subsection{Additional aspects connected to river floods characterization}

River floods behavior is a complicated phenomenon. In order to characterize it properly, following aspects must be determined: a) floods wave origin and related initial flood parameters; b) the river bed and floodplain area specifics; c) floods wave discharge, time of appearance and propagation; and d) flood impacts.

Related data and information are used for the floods events and affected zones description and the event severity evaluation. For this purpose various types of initial data and information must be gained. Some of it can be gained by the implementation of direct measurements and monitoring, other can be obtained by additional assessments.

- Specification of floods origin

This is an important task connected to the related meteorological situation in the observed area. For this purpose the available precipitation data must be gathered and analyzed. Such data can be collected from the precipitation, weather and climatic monitoring stations by installing different types of rain gauges such as the weighing type, float type, tipping-bucket gauge, rainfall-intensity recorder, acoustic type gauges, radars (Doppler, multi-parameter, weather radars) or using satellites data [13-17].

Considering the particular river bed state and its hydraulic properties is also important. The conditions of the surrounding environment must also be considered - elevation, ground coverage - state and hydraulic parameters, existing structures and related possible floods conductive circumstances.

It is possible outer non natural reasons to be floods cause. For the purpose all floods connected factors must be considered.

- Floods wave quantification

This procedure deals with the event related water quantity determination and its time and spatial propagation. Floods wave quantity is the amount of water that passes during the occurrence of the event. It can be obtained conventionally for river discharge monitoring data or determined by other methods. Discharge measurements and observations are conducted in specific monitoring points. Taking into account the local specifics and related river bed hydraulic conditions, the most suitable discharge measurement method, measurement procedure and equipment are selected [13, 15-22]. The result of these types of measurements is flow rate for a specific point. In case of a continuous monitoring the river hydrograph can be obtained along with the discharge rate, volume and stage, time of beginning and time of duration of the event.

In practice discharge monitoring networks cover a number monitoring points and it is very likely the obtained measurements data to be insufficient to describe the overall flood event. In such cases the flood wave specification can be obtained by implementation of various modeling programs based on the already presented hydraulic theoretical base.

- Hydrological evaluations

When investigating the natural character of the flood phenomenon the focus is on the overflow events over a specific threshold followed afterwards by determining the recurrence intervals and probabilities of occurrences [13, 15-17, 23-25]. The floods are classified by the recurrence intervals, probabilities of occurrences and the related thresholds (see Table 1).

Recurrence intervals are based on the probability of the peak streamflow occurrence at a given location in any year. Initial information for such studies are data obtained from the river gauging stations. In case of data absence for ungauged sites, regionalized streamflow statistics methods are used. Most commonly used methods are the: a) index-flood procedure, b) ordinary-least-squares regression procedure, c) weighted- and generalizedleast-squares regression procedure and d) region-of-influence procedure. Recently some methods using satellite images for floods events characterization are also developed. Of 
importance is to account that the flow at any particular point depends on local river bed and floodplain conditions with regard to the riverbed slope, floodplain shape, impoundments of streamflow, existing river regulation structures or reservoirs, water intakes and transfers, etc. At the locations where the stream channel widens or contains dense vegetation, the water velocity may decrease, the flood peak moves downstream, the water can overflow related floodplain where it can be stored until the water level begins to recede. Once the water level decreases, the stored water in the floodplain typically slowly re-enters the stream from the banks. As a result downstream flood flow peak may be modified and less in magnitude but longer in duration. These presented specifics must always be considered in case of floods wave propagation studies with regard to the most appropriate investigation scheme that should be selected.

Table 1. Flood recurrence intervals and probabilities of occurrences

\begin{tabular}{|c|c|c|c|}
\hline \multicolumn{4}{|c|}{ Recurrence intervals and probabilities of occurrences } \\
\hline $\begin{array}{c}\text { Recurrence interval, } \\
\text { in years }\end{array}$ & $\begin{array}{c}\text { Probability of } \\
\text { occurrence in any } \\
\text { given year }\end{array}$ & $\begin{array}{c}\text { Percent chance of } \\
\text { occurrence in any } \\
\text { given year }\end{array}$ & $\begin{array}{c}\text { Annual } \\
\text { exceedance } \\
\text { percentage }\end{array}$ \\
\hline 100 & 1 in 100 & 1 & 1 \\
\hline 50 & 1 in 50 & 2 & 0,50 \\
\hline 25 & 1 in 25 & 4 & 0,25 \\
\hline 10 & 1 in 10 & 10 & 0,10 \\
\hline 5 & 1 in 5 & 20 & 0,05 \\
\hline 2 & 1 in 2 & 50 & 0,02 \\
\hline
\end{tabular}

\subsection{Floods impacts. Balkan experiences}

Floods are events that could occur every year, especially after large precipitation events or snowmelt. In natural conditions they are part of the river flow regime and the water cycle. Anthropogenic works and the operation or destruction of artificial structures can also cause floods. Severe nature phenomenon, such as earthquakes and volcanoes, or man caused environmental modifications, e.g. detonations or explosions, can also lead to floods. So some of the events are natural but others completely differ and would not appear in "normal" river and floodplain conditions. The result of all presented causes depends on the floods severity and local conditions. Overall, flood impacts always must be studied at a local scale.

Floods impacts can have a positive impact, considering that the floodplain is watered and enrichment by the minerals from rivers sediments. They can also have a negative impact, considering the severe impacts and possible damages they cause. The following results after a flood on the affected river channel and surrounding floodplain areas can be observed:

- $\quad$ rivers aquatic and related terrestrial ecosystems disturbance;

- river banks erosion and landslides;

- $\quad$ sediment introduction by landslides and downstream aggradation;

- $\quad$ river bed hydraulics modification; 
- $\quad$ existing artificial structure damage or collapse (bridges, levees, roads, etc.);

- $\quad$ artificial dam failure;

- local areas isolation.

Additionally floods flow can cause damages on the surrounding environment and forests, on the pastures, reduce agricultural production, fences, farm buildings and houses, equipment and animals and urban areas (existing buildings and houses, roads, electricity, water supply and sewage infrastructure, communications, etc.). Some other related impacts are: evacuation of people and animals, people and animals victims, social disruption and financial costs. Their range closely depends on the floods severity, thus the proper event characterization must account for them in the related assessment process.

To illustrate the above mentioned points flood event cases from Bulgaria and Greece are presented. These were selected to illustrate different aspects of the floods phenomenon and related consequences.

\subsubsection{Batulijska River: Bulgarian Case Study}

The flood event on Batulijska River that occurred on August $1^{\text {st }} 2014$ was selected. Purposefully a large river was not selected. The idea was to present how flood event caused by extremely heavy rain precipitations, impact very seriously the environment at a medium scale to observed river.

Batulijska River is a tributary to the Iskar River. It runs near Murgash hut, situated in Murgash Mountain, part of Stara Planina Mountain and flows to north-west. After passing the Batulija village it meets Iskar River (Fig. 2).

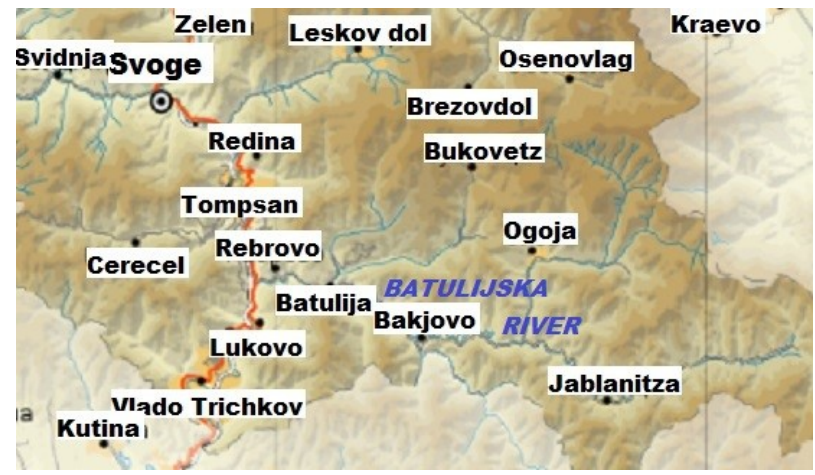

Fig. 2. The location of Batukijska River.

The river length is $40.2 \mathrm{~km}$ and the watershed area is $256 \mathrm{~km}^{2}$. Its annual average flow near Batulija village is $2.7 \mathrm{~m}^{3} / \mathrm{s}$. Four villages are situated downstream the river: Jablanitza, Bakjovo, Batulija, Rebrovo. In Fig. 3 the "normal" flow conditions are illustrated.

The heavy rainfall resulted in the Batulijska River streamflow significantly increasing in several hours. In some places the water level raised up to $1 \mathrm{~m}$. Large areas were flooded including river banks, streets, houses, whole section of villages. Some infrastructure was destroyed such as roads, bridges, electric infrastructure while water supply was interrupted. On August $1^{\text {st }} 2014$ a state of natural disaster was declared in the area for the villages: Vlado Trichkov, Lukovo, Rebrovo, Batulija, Bakjovo, Ogoja, Jablanitza, Bukovetz, Tompsan, Redina and Leskov dol. 


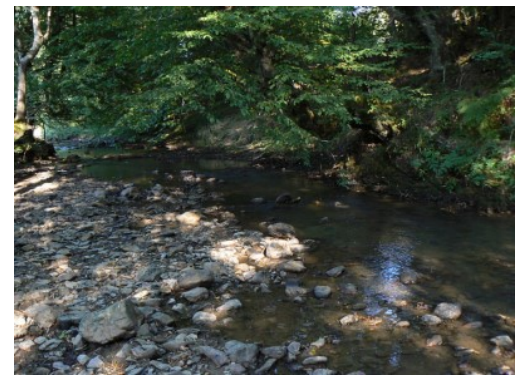

a)

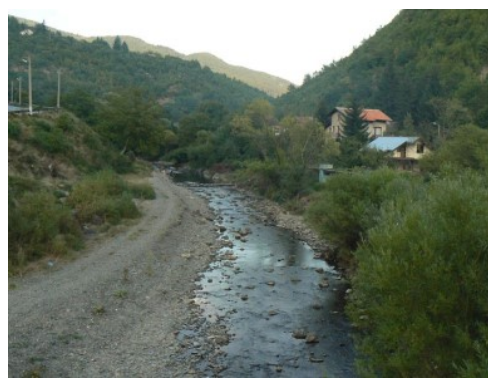

b)

Fig. 3. Batukijska River: a) River streamflow near Jablanitza village during the summer, b) Batulijska River close to the point, where it joins Iskar River during summer flow conditions.

To better understand the process of the flood event and some of related impacts, images are illustrated in Fig. 4-7.

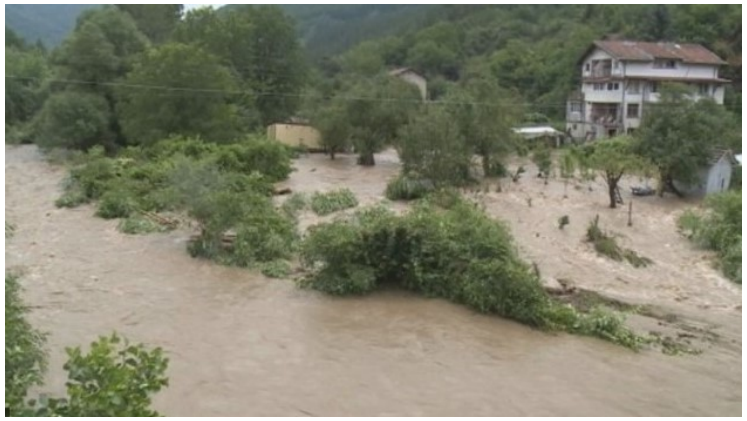

Fig. 4. The Batulijska River flood event in Rebrovo village zone

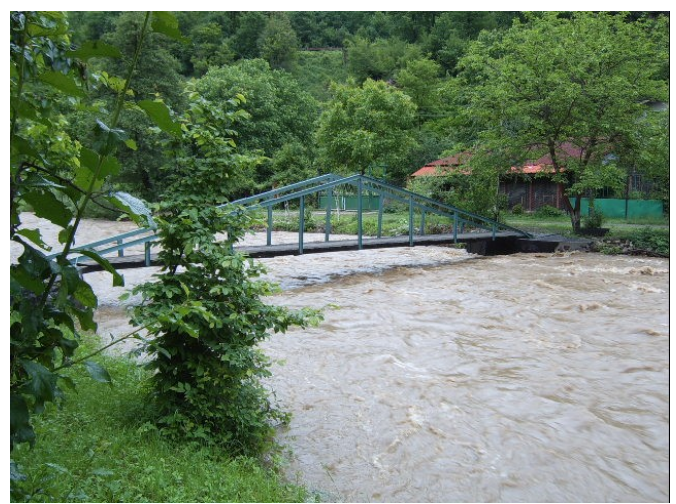

a)

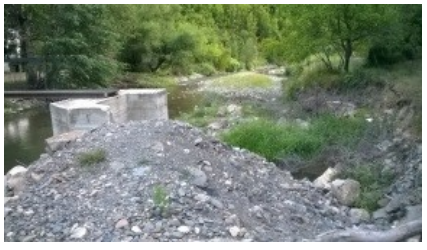

b)

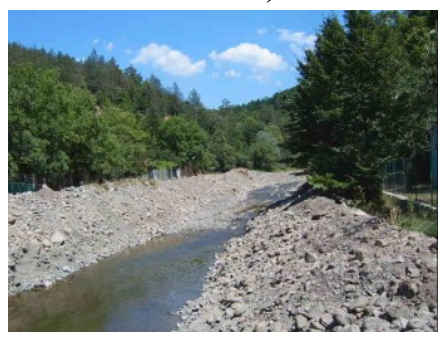

c)

Fig. 5. The Batulijska River flood wave development and its impacts: a) stream water rising in a river segment, b) and c) the same river segment after the flood event - some impacts are evident. 


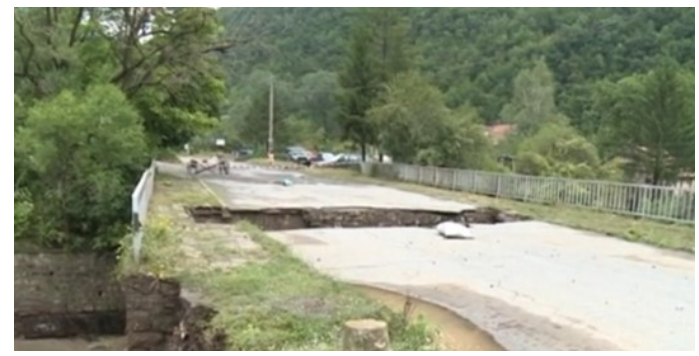

Fig. 6. The Batulija village bridge after the flood event

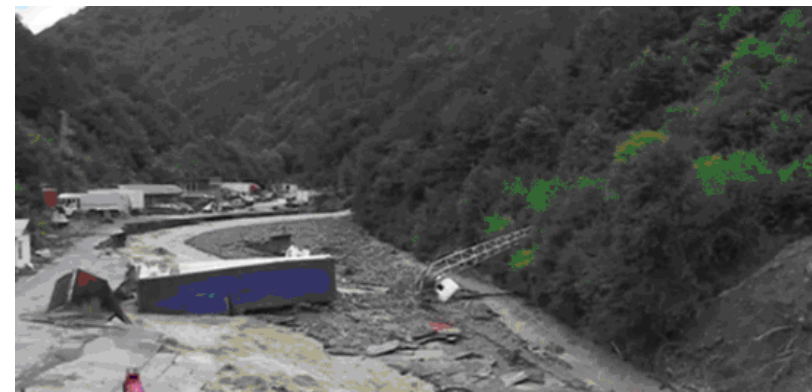

Fig. 7. Flood event damages by the Leskovska River in Leskov dol village, on August $1^{\text {st }} 2014$ that is near the Batulijska River.

These images in Fig. 4-7 illustrate the flood wave time development by showing some of the consequences. The aim is to describe the floods influences on river hydraulics. It is clear that floods can seriously impacts the river bed since after the event it has been totally modified. The significant impacts on the river hydraulics can also be detected. River banks are eroded, huge amounts of the stream load material were deposited downstream, related river bed vegetation is totally destroyed, the river bed profile is changed to a new one with totally different hydraulic properties (cross-sectional area, river bed gradient, river bed roughness, etc.). During the flood some river related and floodplain situated structures and buildings were destroyed. It is possible such structures to lead to a backwater effect and cause additional flood wave rising. The sediment and debris that were transported downstream by the streamflow were either deposited on the specific floodplain area or stopped by some other existing permanent structures. During the process other obstructive occurrences are likely to have been observed causing additional damages. As a result the related flood area was also heavily modified. Consequently the connected natural aquatic and terrestrial ecosystems were also impacted.

The presented images (Fig. 4-7) are to illustrate the changes that occur in the river bed hydraulics and related hydraulic parameters after a flood event. These are of great importance considering that the various parameters are related to the quantitative measurements and assessments with regard to the water level, streamflow rate, etc.

\subsubsection{Evros/Marista River: Greek Case Study1}

The plains that are located in the downstream section or traversed by large rivers (such as Evros, Axios, Nestos, Aliakmon and Peneios) typically face floods impacts in Greece and the Balkans [26]. The discharge volumes of the large rivers often exceed the capacity of the river channels. In this case study, the large floods of the Evros/Marista River were investigated. The total length of the river is $528 \mathrm{~km}$ with $310 \mathrm{~km}$ in Bulgaria and $208 \mathrm{~km}$ 
determining the borders between Greece and Turkey. In regards to the basin $66.2 \%$ belongs to Bulgaria, $37.5 \%$ to Turkey and $6.3 \%$ to Greece [27]. The transboundary nature of the river indicates that only with collaboration of the riparian countries can effective flood mitigation can be achieved.

The last major flood event that started in December 2014 and lasted till May 2015 (Fig. 8). This flood caused 54 houses to be evacuated and 23,000 ha of agricultural fields where flooded because the river levees were broken at 84 points. The flood had a devastating effect on the local economy that depends primarily on agriculture. Major floods have also occurred along the Evros River in 1996, 1997, 1998, 2005, 2006, 2010 and 2012 that indicates that is a repeated problem. Typically these floods and flood waves are more predictable although the overall flood events can last for long periods of time. Still despite being more predictable these problem continues.

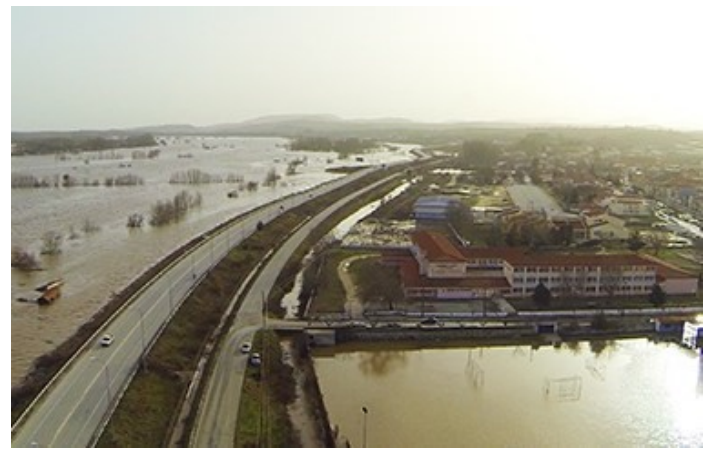

Fig. 8. Breaking of the levees near Sufli led to flooding of the agricultural and rural areas (05/02/2015) that originated from Evros River (source: http://papaioannou-giannis.net).

\subsubsection{Attica Flash Floods: Greek Case Study 2}

Another major category of floods in the Balkans is within the urbanized areas [26]. More than $40 \%$ of flood-related casualties reported in Europe between 1950 and 2006 were from flash floods [28]. In Greece, Athens, Thessaloniki, Patras and Heraklion are located in coastal areas and had above-average flood frequency and an above average number of events [26]. The significant increase in impermeable surfaces in urban catchments as the population exponentially increased in these centers has altered the hydrologic regime (Fig. 9). Infiltration decreases with surface runoff increasing and leading to peak flows (Fig. 1). These types of flood events appear to be on the rise because of the high population density in urban areas, the associated reduction of natural retention areas and the lack of land-use regulations on construction works that are allowed adjacent to the river channels [29].

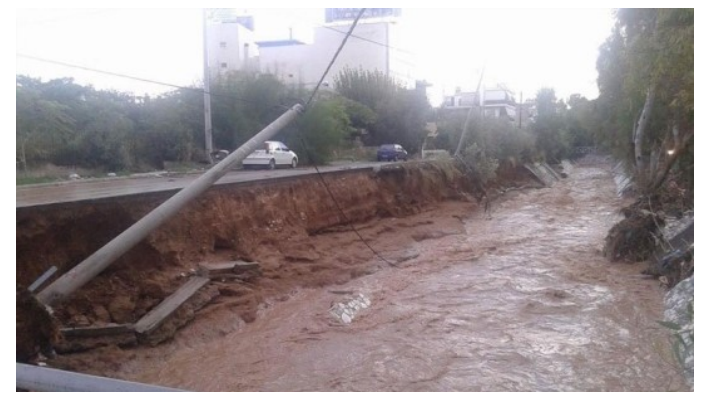

Fig. 9. Urbanization has altered the hydrologic regime and cause flash floods in these environments (source: http://www.zougla.gr). 
Focusing on the prefect of Attica in Greece it had 95 flood events during 1887-2010 that translated in 1 per $40 \mathrm{~km}^{2}$ that was the highest number of flood events per area in the Greece [26]. In addition, this district had 1 flood event per 13 years that was again the highest frequency in Greece for the same period. The most recently flash floods in Athens were in 27/11/2016 and 04/06/2017. The high recurrence and number of flash floods per area is related to rapid with no planning and widespread housing developments. In addition, the mitigation strategy for the prefect seems to be reactive instead of proactive and preventive with little organization and coordination that is unlikely to stop flash floods [30]. At the same responsible authorities appears to not take under consideration the anticipated increase in intensity and rapidity of rainfalls due to climate change at the Attica basin. Large forest fires that frequently happen in the Prefect increase erosion and surface to further enhance flash floods.

The characteristics of these floods are the highly irregular stream flow that can be from zero (no flow) to overflowing the channel in hours. Typically the channels are torrents a characteristics type of water courses in the Mediterranean [31]. While the flooding lasts for a very short period of time, the flood wave can develop very fats and cause major erosional and depositional and because they are difficult to predict can be very catastrophic and lead to losses of human lives.

\section{Prevention and preparedness measures}

To decrease flood impacts and societies vulnerability various measures and tools have been developed. These measures and tools can be separated in two main categories: proactive and mitigation.

Proactive measures aim to characterize flood events in advance in order to be able help direct the mitigation measures. They are two main types - flood watch and early warning systems [24, 32-33]. Such systems deal with the detecting, measuring and determining the phenomenon and its parameters and/or forecasting it. In regards to the starting period and time of occurrence of the phenomenon the following forecasting methods temporal scales are applicable: a) real time (few minutes up to $3 \mathrm{hrs}$ before), b) short-term ( $2 \mathrm{hrs}$ to 5 days before), c) mid-term forecasts (2 to 10 days before) and d) long term (more than 10 days before). In addition, seasonal forecast for several months while ultra-long term forecasts are for up to year or even greater periods. The ultra long forecasts are connected more to the climate change effect studies. They are not directly connected to the early warning systems for flooding.

Other measures that deal directly with the floods physics and its propagation processes are connected to the river systems condition maintenance. This must include the entire river channel and floodplain with respect to: natural rivers, channelization and straightening, longitudinal constructions (dykes and levees), bank reinforcement and embankments, crossprofile structures (dams, weirs, locks/sluices, culverts, and impoundments), etc. The wellmaintaining of their physical state and hydraulics conditions is connected to the river bed hydraulics and channel morphometry state with respect to dredging and mineral extractions, land drainage and sealing, etc.

The importance of mitigating flood events is also evident in the large amount of legislation and administrative works that are currently enforced and elaborated. For the EU Countries the flooding issues has been addressed mainly with two Directives. Specifically the first was the Water Framework Directive 2000/60/EC [1] that addressed flooding issues indirectly. The Flood Directive 2007/60/EC [2] focus on the assessment and management of flood risks. Of course there are additional documents that address this problem [34-37]. Respectively flood related problems are also considered in the national legislation too [3840]. As a result, complex related documents and measures are elaborated in the context of 
the River Basin Management Plans and their second stage, Flood Risk Management Plans, Flood Risk Maps, etc. [41-48]. In Bulgaria floods related specifics were considered for the whole country waters with regard to the River basin management plans, 2016-2021 and Flood risk management plans [41-44] prepared by the four River basin directorates. In Greece, the identification of the highly vulnerable to flooding areas has been completed in the 14 Water Districts of the country [45]. All presented documents are prepared following the scientific and expert works in the area, considering local problems and national specifics.

In order for the above legislations and regulations to be more effective implementation at the national, regional and local level taking into to consideration the local watershed specifics and vulnerability assessments and developing the appropriate structural and nonstructural measures. To achieve this, preliminary field investigations at the specific vulnerable reaches must be done. The measures that are implemented need to be based on the hydro-morphology of the river reaches and the related floodplain. In regards to rivers the main activities, are inspection and maintenance of the existing channel and adjacent infrastructure, and implementing restoration measures when needed. These measures can include river channel and bank maintenance, such as removing the riparian debris, growing trees and shrubs and deposited sediment, preventing erosion from the river banks, trimming the grass and vegetation, clearing banks from obstructions, providing adequate sediment capacity for the downstream flow, estimating ecological flows, constructing protective measures for the existing structures, etc. In case the flood event creates a new channel (alluvial deposit, existing river meanders rupture, etc.) it is possible to restore the original river channel. Some natural water retention measures are also applicable [46]. All presented measures need to be implemented with respect to the local ecosystems well being, thus additional measures such as the ecological river flows should be considered.

\section{Conclusion}

Floods are episodic events that occur by natural or anthropogenic reasons. Their nature follows the main principles of hydrodynamics. To better understand such events the main triggers connected to the flood occurrence, behavior and characteristics and the applicable methods need to be determined. In addition, the theoretical basis for the phenomenon propagation in time and space and main methods that are used were presented. The focus was on applicable practical systems for flood watch and early warning. Accounting the importance of recognizing the river hydraulic parameters when implementing assessment methods, a special attention on flood impacts on the river channel and the related floodplain hydraulics should be taken. The main problems caused by floods are summarized and to enhance clarification, some real cases from the Balkans, specifically from Bulgarian and Greece are presented. Recognizing the phenomenon's importance and its social impacts are also related to the legislative and administrative aspects. A better interconnection between flood regulation and legislation and applicable practical solutions is needed and should be obtained at the national, regional and local scale. Another important aspect to mitigate floods is river maintenance and restoration. Finally, state of the art methods should be implemented by experts in the field while taking into account the appropriate policy and decision making. Such material can help develop early warning and decision support systems that enhance flood mitigation by improving preventive and preparedness measures.

\section{Acknowledgement}

We want to express our gratitude to all colleagues from the Institute of Mechanics - BAS for their support and assistance in the article preparation and good partnership creation. 


\section{References}

1. Directive 2000/60/EC of the European Parliament and of the Council establishing a framework for the Community action in the field of water policy, EC, 22.12.2000;

2. Directive 2007/60/EC of the European Parliament and of the Council of 23 October 2007 on the assessment and management of flood risks (Text with EEA relevance). OJ L 2228/27, 6.11.2007

3. G. K. Batchelor, An introduction to fluid dynamics (Cambridge University Press, (2000)

4. R. W. Jeppeson, Simulation of Steady and Insteady Flows in Channels and Rivers. (1974). Reports. Paper 301. http://digitalcommons.usu.edu/water_rep/301

5. I. Popesku, Computational Hydraulics. Numerical Methods and Modelling (IWA Publishing, 2014).

6. M. Feistauer, Theory and Numerics for Problems of Fluid Dynamics (Charles University, Prague, 2006)

7. H. Lamb, Hydrodynamics (Cambridge Univercity Press, $6^{\text {th }}$ ed., 1994)

8. Y. Nakayama, and R. F. Boucher, Introduction to Fluid Mechanics (ButterworthHeinemann Linacre House, member of the Reed Elsevier plc group, 2000)

9. E. Marinov E., B. Kazakov, M. Maradjieva, and I. Minkov, Hydraulis (VIAS, Sofia, 1994)

10. O. Gunduz, Numerical Solution of Flow Equations. ENV5056 Numerical Modelling of Flow and Contaminant Transport in Rivers.

11. Th. M. Walski, Th. E. Barnard, S. R. Durrans, and M. E. Meadows, Computer Applications in Hydraulic Engineering (Heisted Methods Inc., Waterbury-USA, 19972002)

12. M. S. Horritt and P. D. Bates, J. of Hydrology 268, 87-99. Elsevier (2002)

13. WMO No. 1044 Manual on stream gauging. Vol. I Fieldwork. (WMO, G., Switzerland, 2010)

14. NASA. Global Precipitation Measurement. https://pmm.nasa.gov/science

15. E. M. Shaw, Hydrology in Practice (Chapman \&Hall, L. 1994)

16. E. M. Wilson, Engineering Hydrology (The Maximilian Press Ltd., L., 1980)

17. B. Marchinkov, Hydrology (Technika, Sofia, 1973)

18. R. Herschy, Streamflow Measurement (Elsevier Applied Science Publishers Ltd., Cambridge, 1995)

19. M. Chilikova-Lubomirova, 2009. Metrological evaluation of the methods for discharge measurements and observation, PhD Thesis. IWP-BAS. Sofia.

20. V. D. Bykov, Hydrometrics (Hydrometrical edt., Leningrad, 1949)

21. G. Jolankai, Hydrometric Field Studies for Catchments Basin Exploration (VITUKI, Budapest, 2002)

22. Str. Gerasimov, Methods for analysis and evaluation of the maximum river discharge. (NIMH, Sofia, 1988)

23. R. R. Jr. Holmes and K. Dinicola. 100-Year Flood - It's all about Chance. Haven 't we already had one this century? (USGS, USA, 2010)

24. J. Szolgay, K. Hlavcova, S. Kohnova and G. Balint. Hydrological modelling and forecasting. Handouts for lectures (VITUKI, Budapest, 2001)

25. E. Monev and M. Chilikova-Lubomirova, Flood risk - hydrotechnical aspect. Research project (IWP-BAS, Sofia, 2008)

26. K. Karagiorgos, Fuchs, S., Thaler, T., Chiari, M., Maris and F., Hübl, J., A flood hazard database for Greece. Wildbach Lawinenverbau 170, 264-277 (2013)

27. K. Chouvardas K. and Ch. Papapostolou, Geografies 27, 44-71 (2016)

28. J. I. Barredo, Nat. Hazards 42 (1) 125-148 (2007) 
29. J. Ganoulis, Int. J. of River Basin Management 1, 1-41 (2003)

30. O. Lasda, A. Dikou, and E. Papapanagiotou, Ambio, Springer 39 (8) 608-611 (2010)

31. D. Emmanouloudis, J. L. García Rodríguez, G. N. Zaimes, M. C. Giménez Suárez, and E. Filippidis, K.E. Richards (Ed.) Euro-Mediterranean torrents: Case studies on tools that can improve their management, In: Mountain Ecosystems: Dynamics, Management and Conservation (Nova Science Publishers, Inc, Hauppauge New York, USA, 1-44, 2011)

32. R. Sprague, MIS Quarterly. 4 (4), 1-26 (1980)

33. M. Chilikova-Lubomirova, SGEM Conference proceedings, 3 (1), 621-628 (2016)

34. COM (2004) 472 final. COMMUNICATION FROM THE COMMISSION TO THE COUNCIL, THE EUROPEAN PARLIAMENT, THE EUROPEAN ECONOMIC AND SOCIAL COMMITTEE AND THE COMMITTEE ON THE REGIONS. Flood risk management. Flood prevention, protection and mitigation. Brussels, 12.07.2007

35. TR-2009-040. CIS FOR THE WATER FRAMEWORK DIRECTIVE (2000/60/ec). Guidance document No. 24. RIVER BASIN MANAGEMENT IN A CHANGING CLIMATE. EC. 2009

36. TR - 2013-071 Guidance for Reporting under the Floods Directive (2007/60/EC), EC, 2013

37. TR-2014-082, EU policy document on Natural Water Retention Measures, EU, 2014

38. Water act. SG67/27.07.1999, last amend. S.G.61/11.08.2015

39. Environment protection Law (latest amendm. SG No. 98/28.11.2014)

40. Gazetter of the Hellenic Republic Government. $2^{\text {nd }}$ Issue, No. 1108. Published July 21, 2010

41. Flood Risk Management Plan 2016-2021 (2016) Danube River Basin Directorate, http://www.bd-dunav.org/content/upravlenie-na-vodite/upravlenie-na-riska-otnavodneniia/plan-za-upravlenie-na-riska-ot-navodneniia/

42. Flood Risk Management Plan 2016-2021 (2016) East Aegean River Basin Directorate, http://earbd.org/indexdetails.php?menu id=611

43. Flood Risk Management Plan 2016-2021 (2016) West Aegean River Basin Directorate, http://www.wabd.bg/index.php/2015-06-25-12-30-02/2016-2021

44. Flood Risk Management Plans 2016-2021. (2016) Black Sea River Basin Directorate, http://www.bsbd.org/bg/page purn bsbd.html

45. Greek Ministry Of Environment, Energy And Climate Change. Special Secretariat Of Waters. 2012. Implementation Of Directive 2007/60 /EC. Preliminary Assessment of Flood Risk. Athens, GREECE

46. M. Zelenakova, D. Diaconu and K. Haarstad. ScienceDirect 190, Elsevier Ltd., 420426 (2017) 